\title{
El Ecoturismo y los factores de influencia en la experiencia turística durante excursiones en áreas naturales: Laguna del Quilotoa
}

Ecotourism and influencing factors in the tourist experience during excursions in natural areas: Laguna del Quilotoa

Carmen Isabel Vaca Vaca. ${ }^{1} \&$ Johanna Gabriela Monge Martínez. ${ }^{2}$

Recibido:01-06-2020 / Revisado: 15-07-2020 /Aceptado: 03-08-2020/ Publicado: 04-09-2020

\begin{abstract}
.
DOI: https://doi.org/10.33262/concienciadigital.v3i3.2.1407

Introduction. The UNWTO definition regarding the term "ecotourism", involves all forms of tourism that allow the enjoyment of the landscape richness, but at the same time, there is awareness and minimize the ecological footprint of the tourist. Objective. To analyze the factors that affect the tourist experience in the natural resource called Laguna del Quilotoa, which has a great acceptance of landscape beauty and is part of the tourist attractions of the Los Ilinizas Ecological Reserve, located in the Zumbahua. Methodology. The research was based on a review of statistical data obtained from the Ministry of Tourism, Ministry of the Environment, Central Bank of Ecuador, in order to highlight the relevance of tourism in the country, and of course, the number of visitors to the Los Ilinizas Ecological Reserve. Thus, the bibliographic review of scientific articles was carried out. Conclusion. The analysis of the factors that affect the tourist experience has led to the generation of tourism products being approached from 2 approaches that the tourist seeks, covering their basic needs, the need to travel, simply changing their environment, and, the second approach that is necessary to stop to analyze on the emotions of the tourist, as if it were a life of extraordinary floating and thus generate a comprehensive tourist experience. It is imperative that tourism managers objectively manage the reality of the product if it is under development or is a developed product, and ensure the quality of the tourism product, since the imagery of tourism managers may differ from visitors This aspect is important to open up new panoramas of attraction for visitors.
\end{abstract}

Key words: Ecotourism, tourist experience, incidence factors.

\footnotetext{
${ }^{1}$ Universidad Técnica de Ambato. Facultad de Ciencias Humanas y de la Educación, Carrera de Turismo. carmenivacav@uta.edu.ec

${ }^{2}$ Universidad Técnica de Ambato. Facultad de Ciencias Humanas y de la Educación, Carrera de Turismo, jg.monge@uta.edu.ec
} 


\section{Resumen.}

Introducción. La definición de la OMT respecto al término "ecoturismo", involucra toda forma de turismo que permita el disfrute de la riqueza paisajística, pero a la vez, exista la concienciación y minimizar la huella ecológica del turista. Objetivo. Analizar los factores que inciden en la experiencia del turista en el recurso natural denominado Laguna del Quilotoa que cuenta con una gran aceptación de belleza paisajística y forma parte de los atractivos turísticos de la Reserva Ecológica Los Ilinizas, ubicada en la Parroquia Zumbahua. Metodología. La investigación se basó en revisión de datos estadísticos obtenidos del Ministerio de Turismo, Ministerio del Ambiente, Banco Central de Ecuador, para poder destacar la relevancia del turismo en el país, y por supuesto, el número de visitantes a la Reserva Ecológica Los Ilinizas. Así mismo, se realizó la revisión bibliográfica de artículos científicos. Conclusión. El análisis de los factores que inciden en la experiencia del turista ha conllevado a que la generación de productos turísticos se plantee desde 2 enfoques que busca el turista, cubrir sus necesidades básicas, necesidad de viajar, de simplemente cambiar de ambiente, y, el segundo enfoque que es necesario detenerse a analizar sobre las emociones del turista, como si tratara de una vida de flotación extraordinaria y de esta forma generar una experiencia turística integral. Es imperante que los gestores turísticos manejen con objetividad la realidad del producto si está en proceso de desarrollo o es un producto desarrollado, y asegurar la calidad del producto turístico, puesto que el imaginario de los gestores turísticos puede diferir de los visitantes Este aspecto es importante para abrir nuevos panoramas de atracción para los visitantes.

Palabras clave: Ecoturismo, experiencia turística, factores de incidencia.

\section{Introducción.}

El Ecuador cuenta con varias potencialidades entre ellas, la ubicación en una zona estratégica de América Latina, atravesado por la línea ecuatorial a $22 \mathrm{Km}$. al Norte de la ciudad de Quito (INOCAR 2012). En relación a la proporción del planeta ocupa un área equivalente al 0,06\% de la superficie INABIO (2017), reconocido como uno de los 20 países megadiversos, según lo menciona la Secretaría del Convenio sobre la Diversidad Biológica (2014) y el primero de ellos con la mayor densidad de especies por unidad de área. Son suficientes razones para el planteamiento de estrategias que permitan el aprovechamiento sostenible de todas las riquezas paisajísticas que posee el país.

El trabajo aunado del Estado con la empresa privada ha permitido que el desarrollo de la actividad turística en el Ecuador vaya marcando de forma paulatina un posicionamiento que se ve reflejado en el aporte económico bastante importante. Como lo demuestran las cifras de la contribución total del turismo al PIB en el Ecuador que alcanza el 5,51\% de los cuales el 2.28\% es de tipo directo, lo que representa la tercera fuente de ingresos no petroleros, en base a los datos proporcionados por el Ministerio de Turismo en la rendición de cuentas del año 2018. Cabe destacar que los servicios de alojamiento y alimentación durante el año 2019 se 
expandieron en 2,3\% respecto a 2018 por un incremento de $1,6 \%$ en la llegada de extranjeros al país, de acuerdo a datos del Banco Central del Ecuador (2019).

El incremento del PIB en el país durante el año 2019, hace referencia al incremento de llegadas de extranjeros que, en base a los datos publicados por el Ministerio de Turismo, entre enero y noviembre de 2019 se registró el ingreso de 1.381.726. Los viajeros provienen especialmente de países como Estados Unidos, España, Alemania, Canadá y Francia y por ende el crecimiento del PIB durante el año 2019 fue del 1.8\% en relación al del año 2018 que fue de 1,7\%. Incremento significativo que requiere a la vez fortalecer y potencializar la actividad turística en el territorio ecuatoriano.

Ahora bien, es necesario realizar una mirada hacia los atractivos turísticos que forman parte de las áreas protegidas en el Ecuador, en base a los datos proporcionados por el Ministerio del Ambiente durante el año 2019 se ha contado con 1.804 .198 visitantes en las 30 áreas protegidas donde se registran las visitas. El presente estudio se centra en la Reserva Ecológica Los Ilinizas que, durante el año 2019, contó con 16.865 visitas de turistas extranjeros y 69.496 visitas de turistas nacionales (SUIA 2019). Al realizar una comparación se puede observar que el mayor porcentaje lo componen los turistas nacionales. Sin embargo, la población de turistas extranjeros que visita la reserva pese a ser menor que de los turistas nacional, se transforma en un indicador de la gran acogida de esta área.

La Reserva Ecológica los Illinizas está compuesta por un volcán con dos cumbres, un cerro en forma de corazón y una laguna de color verde turquesa (SNAP 2020). El presente análisis se enfoca exclusivamente en uno de los principales atractivos naturales de esta reserva como lo es la Laguna del Quilotoa. Este recurso natural forma parte de la Reserva Ecológica Los Ilinizas, como lo describe en la Resolución No. 66 del 11 de diciembre de 1996, publicada en el Registro oficial No. 92 del 19 de diciembre de 1996. El Ministerio de Turismo (2017), hace referencia incluso que en la revista Twisted Sifter, se publica que la Laguna de Quilotoa, se encuentra entre los "15 de los más hermosos lagos volcánicos en el mundo". Otra página como Tripadvisor en sus estadísticas de opinión de 1.188 datos visualizados, 949 visitantes le dan una valoración de excelente, lo que representa el $80 \%$ de turistas satisfechos durante la visita al sitio.

Si bien es cierto, el análisis que se ha realizado se lo ha hecho en función del valor paisajístico con el que cuenta la Laguna de Quilotoa; pero no solamente es la naturaleza, pues se debe destacar el paisaje cultural como contraste a este sitio natural. Tomando como referencia la publicación del Gobierno Autónomo Descentralizado Parroquial Rural de Zumbahua, se destacan recursos turísticos naturales como el cañón Toachi, termas Chicho, de hecho, muy poco promocionados; en cuanto a los atractivos culturales. La Parroquia de Zumbahua cuenta con famosos personajes conocidos como "pintores de Tigua", realizan pinturas en cuero de oveja y madera; para realizar vistas panorámicas se cuenta con el mirador Kapawana, el mirador de cristal Shalala; además la feria indígena que se realiza los días sábados, que llena de colorido al paisaje natural. 
Tanto la categorización, como las estadísticas de visitantes satisfechos al visitar la Laguna de Quilotoa, le dan razones suficientes, para que combinadas con un adecuado plan de manejo sostenible también podría considerarse un sitio para la certificación como destino sostenible por Tour Cert empresa alemana que se basa en los principios de sostenibilidad y responsabilidad social empresarial, con el fin de incrementar el desempeño sostenible en el sector, difundir el turismo sostenible basado en la responsabilidad social como lo han alcanzado destinos como la parroquia San Joaquín del Cantón Cuenca, provincia del Azuay MINTUR (2019).

En base al análisis realizado sobre las estadísticas del turismo en el Ecuador y la gran relevancia paisajística que posee la Laguna de Quilotoa, es necesario realizar un análisis sobre algunas variables de estudio como el ecoturismo y la experiencia turística; así como también, identificar cuáles son los factores que influencian en dicha experiencia. Como referente se ha tomado la laguna del Quilotoa, vinculado con la práctica del ecoturismo que se puede realizar en esta zona.

Inicialmente se plantean dos interrogantes: ¿Qué es el ecoturismo?; y, ¿por qué relacionarlo con la experiencia turística? Para los autores Wo Ching y Rhodes (2009), el término ecoturismo resulta de dos palabras: ecología y turismo, en vista de que la ecología hace referencia al estudio de las interacciones entre los seres vivos con su entorno; y, turismo se relaciona más bien con la acción de viajar a un sitio con el fin de recrearse. En el Reglamento Especial de Turismo en Áreas Naturales Protegidas en el Art. 31, se encuentran dos ítems que hacen diferencia entre la práctica del turismo de naturaleza (numeral 1) y Ecoturismo (numeral 3), el primero se diferencia en la contemplación y esparcimiento y el segundo en la visita a áreas naturales con bajo impacto y sobre todo que se propicie el involucramiento activo y socioeconómico en beneficio de las comunidades locales. Si se lo quiere ver desde dos perspectivas el turista es considerado como un espectador tanto del paisaje natural como cultural, mientras que quien practica el ecoturismo se hace parte de la comunidad respetando el área natural.

La Real Academia de la Lengua (2020), define a la experiencia como: hecho de haber sentido, conocido o presenciado alguien algo; esta concepción se considera como la más cercana a las emociones que puede generar la práctica del turismo en el turista. La OMT (2017), manifiesta que, la combinación de todos los elementos parte del producto en este caso ecoturístico debe generar una experiencia turística integral, con elementos emocionales, para los posibles clientes. La Cumbre Mundial del Ecoturismo (2002), recomienda concienciar a las comunidades locales sobre las iniciativas ambientales, esta estrategia garantiza la calidad en la experiencia turística.

El análisis de la experiencia turística, es un estudio que se convierte en una antesala para la generación del producto turístico, como resultado de una adecuada gestión de la cadena de valor. Flores (2009) menciona que no es más que el conjunto de actividades interrelacionadas que se desarrollan en el mismo y añaden valor a la experiencia turística. 
Desde el enfoque de producto turístico, es necesario hacer hincapié la complejidad del mismo, puesto que abarca elementos intangibles, en forma de servicios (De la Ballina 2017). Para ser generadores de una experiencia turística memorable es donde la generación del producto turístico debe partir desde la concepción de vivencias memorables, más allá del eslogan "el viaje soñado" en "viaje vivido" y es donde la comunidad receptora que no solo abarca el espacio geográfico y sus habitantes, sino que también las características propias de estos y las relaciones y manifestaciones que se generen entre los habitantes de las mismas (Monterrubio 2009). En si la generación de una experiencia satisfactoria de lo auténtico en la naturaleza, la cultura, la gente o una combinación de las mismas (Santana 2003), lo que requiere la implementación de políticas desde el estado hacia las diferentes funciones y roles que pueden cumplir las comunidades aledañas a las áreas naturales como es el caso de la Parroquia de Zumbahua que cuenta con 13 comunidades de acuerdo a datos del Gobierno Autónomo Descentralizado de la Parroquia Rural Zumbahua (2020).

En este caso las empresas intermediadoras juegan un rol importante de compromiso y actuación con responsabilidad social, pues al momento de realizar el empaquetamiento del viaje, deben establecer diferencias entre la organización de un viaje combinado que incluye transporte, alojamiento, entre otros elementos significativos del tour (Ocaña 2012). La programación de un ecotour involucra a más de los elementos antes descritos en el tour, incluye en su filosofía de planificación y acción la ética de ser un producto ambiental y socialmente responsable (Wo Ching y Rhodes 2009). El llamado a las empresas intermediadoras en ayudar a promover la práctica del ecoturismo con los condicionantes que involucra más allá de un cálculo de rentabilidad para sí mismas.

Para el diseño del producto turístico, cabe resaltar cinco categorías genéricas con posibles combinaciones detalladas por Maldonado (2005), identificar los elementos naturales y culturales que sobresalen, la innovación, servicios que se ofrecen al turista, servicios conexos, circuitos turísticos y conexión con otras comunidades, identificar de forma transparente si el producto está en proceso de consolidación o ya está consolidado.

Estas pautas presentes como parte de una planificación organizada y participativa con la comunidad permitirá llegar a la expectativa del turista que visita un área protegida, sabiendo que el interés es elevado de quien visita estas zonas, pues esto requiere un reflexión por todos los involucrados en la planificación y organización, en el hecho de que el grado de satisfacción mostrada por los visitantes a zonas rurales se relaciona con el entorno, con las tradiciones y la riqueza cultural de la zona visitada, como se evidencia en el estudio en Navarra realizado por García y Barrena (2013), sin embargo, requiere detenernos en las actividades que los turistas estarían dispuestos a realizar, y aquellas que no, práctica de agricultura, montar a caballo, conocer la artesanía de la zona, supera el 70\% de rechazo, aproximadamente en un 50\% aceptan realizar senderismo y montañismo. Este comportamiento de un grupo de turistas en España debería ser un referente para detenernos y evitar romanticismos en el diseño ideal de un producto. Estudios como estos, nos ayudan a buscar más allá de lo común, la innovación enfocada en lograr cautivar al turista con lo que se oferta, tanto en servicios como en actividades de interacción. 
Para generar la experiencia del viaje memorable, el diseño y organización del tour o en este caso ecotour, debe tomar en cuenta el valor agregado para el logro del objetivo. Por tanto, será necesario identificar los tipos de experiencias más demandadas en el Ecuador, que en el informe anual de la empresa Trekk Soft (2019), identifica 6 tipos que se detallan a continuación:

1. Experiencias únicas, donde los turistas quieren ser los primeros en explorar destinos exóticos.

2. Tours ecológicos, que son altamente preferidos a destinos que reflejen no tener una causa aparente;

3. Experiencias locales, que identifica a turistas que quieren vivir como residentes locales en términos de comida, vivencias, entre otros;

4. Aventuras;

5. Tours y actividades de varios días;

6. Destinos que reflejen una herencia cultural fuerte.

Tomando en cuenta estos 6 tipos de experiencias, se recordará que una vez que la experiencia turística ha sido capaz de cubrir las necesidades básicas del turista, es decir, las necesidades que le originaron el viaje, otras necesidades más elaboradas y complejas aparecen; es decir, nuevas motivaciones que el turista busca sean satisfechas (Lopes 2006). Para Gravari-Barbas y Graburn (2012), las imágenes y los imaginarios turísticos se entrecruzan en los procesos imaginativos de los turistas y las comunidades locales, lo que permite el logro de estimular la imaginación y pueden facilitar la creación o recreación de lugares turísticos. Sin embargo, también deberá considerarse lo manifestado por Pereiro y De León (2007), que las imágenes de promoción turística pueden ser confirmadas o no por las imágenes de la experiencia del turista, que puede registrar sus propias imágenes y difundirlos o crear otros que bien podrían afectar positiva o negativamente bloqueando el conocimiento y la comprensión intercultural.

Cada vez, se acentúa la concepción de valorar la cultura local en la cual se incluye una diversidad de actividades que representan la autenticidad de las comunidades, tal cual una burbuja, que representa un espacio que proporciona entretenimiento y emoción a los visitantes al mismo tiempo que seguridad y protección, Milano y Travé (2019), circunstancias favorables para que el turista pueda disfrutar a plenitud de cultura y naturaleza. Lo que repercutirá en el logro de la lealtad del cliente, medida a través de la intención de volver al sitito de visita y la comunicación boca a boca de los clientes hacia otras personas (Eithmahl \& Bitner, 2000, mencionado en Gracia \& Grau, 2008).

Respecto al diseño del producto con el tipo de emoción que se desea generar en el turista radicará fundamentalmente en lograr identificar el factor motivacional del turista; así por ejemplo, Suárez et al (2013), identifican 2 tipos de factores motivacionales: factores de empuje, relacionados con aspectos internos y emocionales y factores de atracción, más conectados con aspectos externos, cognitivos y de situación, lo que en el negocio del turismo es importante identificar tanto en la identificación de los destinos turísticos así como de quienes diseñan los viajes sobre estos dos ámbitos interno y externo que se combinan en el rol del turista. 
En el proceso de decisión del turista al comprar un determinado producto o servicio, influyen dos tipos de factores: determinantes relacionados con el ámbito externo al turista, así como personales; así como, los factores motivantes o motivacionales en los que radica las necesidades por las cuales una persona viaja (Pannoso y Lohmann 2012). Se podría concluir que el análisis de los factores viene determinado en dos variantes que se reflejan en factores intrínsecos y extrínsecos del turista. A la hora de diseñar el producto turístico, se debería garantizar el cumplimiento tanto de las necesidades básicas, expectativas del viaje, así como también la parte emocional, tomando en consideración el Art. 2 del Código Ético Mundial para el Turismo que menciona, "el turismo, instrumento de desarrollo personal y colectivo".

Otros factores de gran influencia en el turista son las variables tangibles (monumentos naturales, clima, infraestructuras, arte, etc.) como variables intangibles (libertad, seguridad, relajación, energía, etc.), en este caso cabe resaltar que la vivencia del visitante durante su viaje de turístico debe ser holística, es aquí donde se hace hincapié a lo mencionado en la teoría general de los sistemas de Ludwing Von Bertalanffy la sociedad humana se funda en los logros del individuo, es decir, actualmente la tendencia turística ha pasado de ser lineal a ser más bien constructora de experiencias, rompiendo el guión lineal de un tour básico. Como menciona Gutiérrez, et al, (2013) sobre el MOA (Motivación Oportunidad y Capacidad), la motivación del individuo, la oportunidad observada y sus capacidades-habilidades internas causan la recepción del mensaje y provocan un comportamiento positivo hacia el mismo.

En el estudio de análisis de perfil y satisfacción del turista que visita montañita, si bien es cierto, el destino es diferente al sitio de análisis de esta investigación, pero cabe resaltar que los autores Carvache, Torres, y Carvache (2017), establecen que identificar la motivación y el grado de satisfacción del turista, constituyen referentes importantes de trabajo para lograr un impacto positivo en la experiencia de los turistas cuando realizan la visita.

En este mismo sentido, en la investigación realizada por Matos y San Martín (2012), concluyen que las emociones (agrado) ayudan a incentivar la confianza en un destino turístico. En un análisis del nivel de satisfacción en la práctica de turismo rural Campón y Hernández (2014), llegan a la conclusión que la imagen del destino, o del alto nivel de calidad de servicios incide para lograr la satisfacción y lealtad del turista.

Pese a los ingentes esfuerzos por los organismos del turismo, medir el desarrollo turístico en las zonas rurales, sigue presentando sesgos que no permiten tener la claridad en los datos. El estudio se radica en Hajij Village en Irán, para los que se puede apreciar el nuevo índice basado en los promedios ponderados de 20 variables, tal como se utiliza con una muestra de 87 miembros de la Comunidad Hajij. El estudio explora la posibilidad de mediciones cuantitativas entre las debilidades, fortalezas, amenazas y oportunidades asociadas con los planes de desarrollo (Hashemi y Ghaffary 2017).

\section{Metodología.}

La investigación se basó en revisión de datos estadísticos obtenidos del Ministerio de Turismo, Ministerio del Ambiente, Banco Central de Ecuador, para poder destacar la relevancia del 
turismo en el país, y por supuesto, el número de visitantes a la Reserva Ecológica Los Ilinizas. Así mismo, se realizó la revisión bibliográfica de artículos científicos para poder analizar y contrastar variables como la experiencia turística, el ecoturismo, los factores de incidencia en la experiencia del turista, lo que también fue necesaria la revisión de casos para identificar los factores que inciden en el nivel de satisfacción del turista. También se ha realizado un análisis de cómo medir de forma efectiva el desarrollo turístico en zonas rurales, tomando en cuenta, que estos sitios de igual forma tienen un denominador común que es la naturaleza y la interacción con los turistas.

\section{Conclusiones.}

- El Ecuador cuenta con suficientes recursos turísticos para ser aprovechados de manera responsable con el medio natural y cultural, lo que se requiere es fortalecer a las comunidades y asumir el reto de gestores y promotores del desarrollo del turismo de forma responsable.

- Los factores de incidencia en la experiencia turística, se han identificado dos tipos de factores extrínsecos e intrínsecos que deben ser analizados cuidadosamente a la hora de generar los productos turísticos o programar los itinerarios tanto para el turista como para quien realiza ecoturismo, puesto que, se pudo identificar además el rol del imaginario tanto del turista como de la comunidad receptora, si no existe un análisis minucioso en el que no únicamente se arme un tour o un ecotour sin tomar en cuenta aspectos como el perfil del turista, las expectativas del viaje, simplemente es combinar sitios con actividades. Lo que se requiere en los destinos, atractivos turísticos es verdaderos productos que le permitan el turista obtener un disfrute integral durante su viaje.

- Respecto a la oferta turística en la Laguna de Quilotoa, se puede decir que de las visitas realizadas se ha mejorado el sendero para descender a la laguna, se oferta paseos en canoa quienes como seguridad le entregan chalecos, las caminatas para el ascenso a muchos turistas les hace desistir de avanzar, y se genera una opinión contradictoria como es la contratación de mulas para poder realizar el ascenso, turistas de acuerdo, y otro grupo no de acuerdo, sobre todo por la sensibilización que actualmente se cuenta en el mundo, existe oferta de alojamiento limitada, lo que se ha podido observar es la mejora de servicios de restauración.

- La Parroquia de Zumbahua, realizando un estudio previo del perfil del turista, las expectativas del viaje soñado al viaje vivido, podría cambiar la imagen de un sitio de paso a uno en el que el turista invierta en pernoctación, lo que incentiva a que el gasto turístico sea en mayor proporción.

\section{Referencias Bibliográficas.}

Angulo, S., Guerrero, W., Ramírez, M., Ospino, R., \& Pabuena, M., (2019). La mirada del turista: imaginario y percepción de los turistas que visitan la ciudad de guanajuato. Jóvenes en la ciencia, 1-8. 
Banco Central del Ecuador. (31 de marzo de 2020). Producto Interno Bruto (2019). Recuperado de: https://www.bce.ec/index.php/boletines-de-prensa-archivo/item/1359la-econom\%C3\%ADa-ecuatoriana-creci\%C3\%B3-01-en-2019\#_ftn2

Campón, A., \& Hernández, J., (2014). El turista rural español y sus niveles de satisfacción y lealtad hacia los destinos de turismo rural. Jornadas de Investigación en Turismo, 105 125.

Carvache, W., Torres, M., \& Carvache, M., (2017). Análisis del perfil y satisfación del turista que visita Montañita - Ecuador. Cuadernos de Turismo, 113-129.

Código Ético Mundial para el Turismo. (2001). Adoptado por la resolución A/RES/56/2012, 21 de diciembre de 2001.

De la Ballina, F., (2017). Marketing Turístico Aplicado. ESIC Editorial.

Flores, D., (2009). Competitividad sostenible de los espacios naturales protegidos como destinos turísticos. Un análisis comparativo de los parques naturales sierra de aracena y picos de aroche y sierras de cazorla, segura y las villas. Eumed.net,3-611.

Gobierno Autónomo Descentralizado Parroquial Rural de Zumbahua. (03 de abril de 2020). Zumbahua. Gobierno Autónomo Descentralizado Parroquial Rural de Zumbahua: Recuperado de: http://zumbahua.gob.ec/cotopaxi/

García, T., \& Barrena, R., (2013). Preferencias del visitante de establecimientos de turismo rural.estudio en Navarra. Cuadernos de Turismo, 141-153.

Gracia, E., \& Grau, R., (2008). Estudio de la calidad de servicio como base fundamental para establecer la lealtad del cliente en establecimientos turísticos. Universitat Jaume I, 210.

Gravari-Barbas, M., \& Grabum, N., (2012). Imaginarios turísticos. Via Tourism Review, 1-9.

Gutiérrez, D., Bulchand, J., Díaz, R. \& Parra, E., (2013). Antecedentes del uso de los medios sociales por el turista: motivación, oportunidad y capacidad. Cuadernos de Turismo, 153-173.

Hashemi, N. \& Ghaffary, G., (2017). A proposed Sustainable Rural Development Index (SRDI): LESSONS FROM Hajij village, Iran. Cabi, 130-138.

Instituto Nacional de Biodiversidad. (2017). Agenda Nacional de Investigación sobre la biodiversidad, MAE, SENESCYT e INABIO. Quito. 20pp. Recuperado de: http://www.biodiversidad.gob.ec/wpcontent/uploads/downloads/2018/02/ANIB_final1 compressed.pdf 
Instituto Oceanográfico de la Armada del Ecuador INOCAR. (2012). CAPÍTULO I: Información General de la República del Ecuador. Recuperado de: https://www.inocar.mil.ec/docs/derrotero/derrotero_cap_I.pdf

Jafari, J. (2007). Modelos de Turismo: los aspectos socioculturales. Antropología y turismo. Universidad Autónoma del Estado de Hidalgo. México.

Lopes, E., (2006). La motivación turística: el caso de la región de las aguas termales de Goiás, Brasil. Boletín de la A.G.E., 303-314.

Ludwing, V., (s/a). Teoría General de los Sistemas. Pág. 37.

Maldonado, D., (2005). Pautas metodológicas para el análisis de experiencias de turismo comunitario. Organización Internacional del Trabajo, 33.

Matos, R., \& San Martín, S., (2012). Análisis sobre la reputación de marca, las emociones y la confianza como formadoras de la satisfacción del turista. Contaduría y Administración, 253-286.

Milano, C., \& Travé, R., (2019). A modo de introducción: imagen y experiencia en el turismo. Pasos, 300-330.

Ministerio del Ambiente. (marzo, 2017). Ambiente 2035. Aportes al debate de la política ambiental. No. 006. Recuperado de: https://www.ambiente.gob.ec/wpcontent/uploads/downloads/2017/06/Numero-6.pdf

Ministerio de Turismo. (13 de enero de 2014). Quito. El Quilotoa considerada una de las lagunas más bellas del mundo. Recuperado de: https://www.turismo.gob.ec/elquilotoa-considerada-una-de-las-lagunas-mas-bellas-del-mundo/

Ministerio de Turismo. (27 de octubre de 2017). Cuenca, Azuay. 80 empresas asociadas al proceso de Certificación del Destino Cuenca recibieron distinción. Recuperado de: https://www.turismo.gob.ec/80-empresas-asociadas-al-proceso-de-certificacioninternacional-del-destino-cuenca-recibieron-distincion/

Ministerio de Turismo. (2018). Rendición de Cuentas. 2018. Recuperado de: https://www.turismo.gob.ec/wp-content/uploads/2019/02/InformeRendici\%C3\%B3n-de-Cuentas-2018-MINTUR.pdf

Ministerio de Turismo. (23 de diciembre de 2019). Quito, Pichincha. Promedio de llegada de visitantes extranjeros a Ecuador creció $4 \%$ en 2019. Recuperado de: https://www.turismo.gob.ec/promedio-de-llegada-de-visitantes-extranjeros-a-ecuadorcrecio-4-en-2019/

Ministerio de Turismo. (2019). Informe de tendencias globales en consumo, tecnología y turismo. 2019. Recuperado de: https://servicios.turismo.gob.ec/descargas/Turismocifras/Publicaciones/Tendencias/2019/TENDENCIAS-DE-TURISMO-2019.pdf 
Ministerio de Turismo. (2019). Informe de tendencias globales en consumo, tecnología y turismo. 2019. Recuperado de: https://servicios.turismo.gob.ec/descargas/Turismocifras/Publicaciones/Tendencias/2019/TENDENCIAS-DE-TURISMO-2019.pdf

Monterrubio, J., (2009). Comunidad receptora: elemento esencial en la gestión turística. Revista electrónia UACH,101-111.

Ocaña, I., (2012). Gestión de productos turísticos. Editorial SÍNTESIS, 16

Organización Mundial del Turismo. (2002). Cumbre Mundial del Ecotursimo: Informe Final. (ISBN: 92-844-0565-3). Recuperado de: http://www.unep.fr/shared/publications/pdf/WEBx0079xPA-

EcotourismSummitES.pdf

Organización Mundial del Turismo. (2015). Cumbre Mundial de Turismo Sostenible: Carta Mundial del Turismo Sostenible +20. (26 y 27 de noviembre de 2015). Recuperado de: http://cartamundialdeturismosostenible2015.com/wp-content/uploads/2016/05/CartaMundial-de-Turismo-Sostenible-20.pdf

Organización Mundial del Turismo. (2017). UNWTO Tourism Definitions. (2017). Recuperado de: https://www.e-unwto.org/doi/pdf/10.18111/9789284420858

Pannoso, A., \& Lohmann, G., (2012). Teoría del turismo conceptos, modelos y sistemas. Editorial TRILLAS, p. 291.

Pereiro, X., \& De León, S., (2007). La construcción imaginaria del lugar turístico: Huna Yala. Tareas, 61-96.

Real Academia Española. (04 de abril de 2020). Real Academia Española y Asociación de Academias de la Lengua Española. Recuperado de: https://dle.rae.es/?w=experiencia

Reglamento Especial de Turismo en Áreas Naturales Protegidas. (2016). Decreto Ejecutivo 827. Registro Oficial Suplemento 672 de 19 de enero de 2016.

Resolución No. 66. (2016). Creación de la Reserva Ecológica Los Ilinizas. Decreto 1665. Registro Oficial 341, 25-V- 2004.

Santana, A., (2003). Turismo cultural, culturas turísticas. Horizontes antropológicos,31-57.

Sistema Nacional de Áreas Protegidas del Ecuador SNAP. (2020). Reserva Ecológica Los Ilinizas. Recuperado de: http://areasprotegidas.ambiente.gob.ec/es/areasprotegidas/reserva-ecol\%C3\%B3gica-ilinizas

Sistema Único de Información Ambiental SUIA. (2019). Reporte Consolidado de visitas a las áreas protegidas. Enero - diciembre 2019. Recuperado de: http://suia.ambiente.gob.ec/documents/10179/1232803/Reporte+Registro+Visitas+20 19.pdf/1f40ea38-d528-45ef-9097-059f39333be5 
Suárez, M., Manrique, P., \& Aguiar, T., (2013). Motivación del turista hacia la práctica de deportes náuticos: un estudio en el destino turístico de Gran Canaria. Revista de Análisis Turístico,37-48.

Tripadvisor. (03 de abril de 2020). Laguna de Quilotoa. Opiniones. Recuperado de: https://www.tripadvisor.co/ShowUserReviews-g488181-d2487783-r203659675Laguna_Quilotoa-Cotopaxi_Province.html

Wo Ching, A., \& Rhodes, A., (2009). Manejo y conducciónde grupos de ecoturistas. Editorial Trillas, 9. 


\section{PARA CITAR EL ARTÍCULO INDEXADO.}

Vaca Vaca, C. I., \& Monge Martínez, J. G. (2020). El Ecoturismo y los factores de influencia en la experiencia turística durante excursiones en áreas naturales: Laguna del Quilotoa. ConcienciaDigital, 3(3.2), 47-59. https://doi.org/10.33262/concienciadigital.v3i3.2.1407

\section{LCiencia}

El artículo que se publica es de exclusiva responsabilidad de los autores y no necesariamente reflejan el pensamiento de la Revista Conciencia Digital.

El artículo queda en propiedad de la revista y, por tanto, su publicación parcial y/o total en otro medio tiene que ser autorizado por el director de la Revista Conciencia Digital.
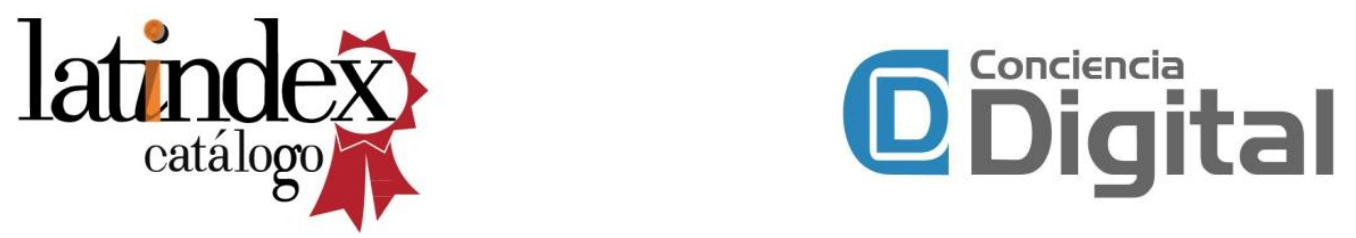